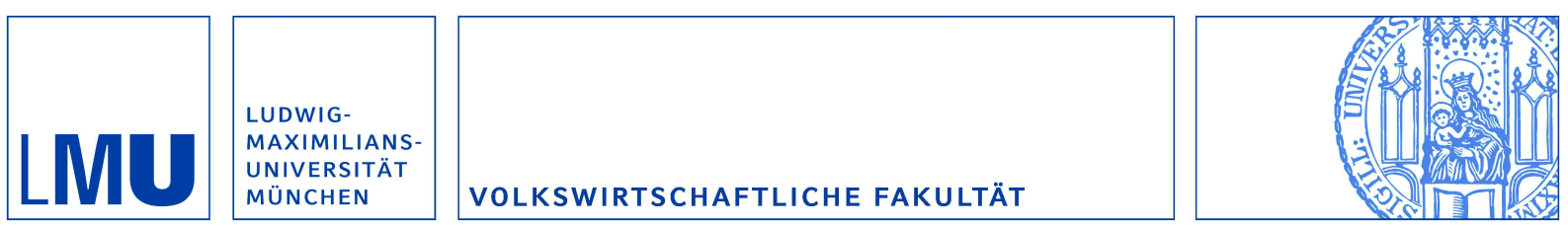

Illing, Gerhard und Siemsen, Thomas:

Forward Guidance at the Zero Lower Bound in a Model of Price-Level Targeting

Munich Discussion Paper No. 2015-1

Department of Economics

University of Munich

Volkswirtschaftliche Fakultät

Ludwig-Maximilians-Universitäł München

Online at https://doi.org/10.5282/ubm/epub.22797 


\title{
Forward Guidance at the Zero Lower Bound in a Model of Price-Level Targeting *
}

\author{
Gerhard Illing $^{\dagger} \quad$ Thomas Siemsen ${ }^{\ddagger}$
}

First Version: December 2013

This Version: February 9, 2015

\begin{abstract}
We study monetary policy at the ZLB in a traceable three-period model, in which pricelevel targeting emerges endogenously in the welfare function. We characterize optimal pricelevel forward guidance under discretion and commitment. Potentially non-monotonic discretionary welfare losses are lowest with perfectly flexible prices. Price-level targeting introduces a new constraint on optimal forward guidance that restricts the credible amount of overshooting. With this constraint, the zero lower bound may be binding even after the shock has abated. We characterize conditions when the commitment to hold nominal rates at zero for an extended period is optimal. Finally, we introduce government spending and show that under persistently low policy rates optimal government spending becomes more front-loaded, while procyclical austerity fares worse than discretionary government spending.
\end{abstract}

JEL classifications: E43, E52, E58,

Key words: zero lower bound, forward guidance, price-level target, optimal policy

${ }^{*}$ We wish to thank two anonymous referees for excellent suggestions. We are also grateful for comments from participants at various seminars and conferences. All remaining errors are our own.

${ }^{\dagger}$ Ludwig-Maximilians-University Munich, Ludwigstr. 28, 80539 Munich, Germany, Illing@econ.lmu.de

${ }^{\ddagger}$ Corresponding author, Ludwig-Maximilians-University Munich, Ludwigstr. 28, 80539 Munich, Germany, Thomas.Siemsen@econ.lmu.de 


\section{Introduction}

With policy rates at close to zero worldwide, central banks in the USA, England, Japan and the Euro Area increasingly resorted to forward guidance (signaling their intention to keep interest rates low for an extended period) as a tool to lower the real rate of interest and to stimulate real activity even when the nominal rate is stuck at the zero lower bound (ZLB). Current central bank policy has been strongly influenced by recent research on optimal policy at the ZLB in New Keynesian models (e.g. Eggertsson and Woodford, 2003; Eggertsson, 2011; Werning, 2012). These models allow analyzing the impact of price stickiness, but they focus almost exclusively on the special case of a Calvo (1983) pricing mechanism.

As is well known, targeting an inflation rate of zero is welfare optimizing in that setting. At the ZLB, it is optimal to commit to target a higher rate of inflation for some time once the ZLB is no longer binding. But as shown by Eggertsson and Woodford (2003), optimal policy under forward guidance is prone to a problem of dynamic inconsistency. Recently, price level targeting has been suggested as a strategy to overcome this problem: under price level targeting, periods of undershooting the target are automatically followed by catching up periods of higher inflation in order to return to target, introducing an automatic stabilization mechanism. ${ }^{1}$

Our paper analyses price-level targeting in a traceable three-period setup. Extending the framework of Benigno (2009), we characterize monetary and fiscal forward-guidance policy in a model, in which price-level targeting emerges endogenously as welfare-optimal policy through the welfare function. To this end, we deviate from the Calvo assumption and assume that firms are ex-ante heterogeneous: a share of firms exhibit long-run price stickiness over the whole model horizon. Nevertheless, in such a regime, similar issues arise as under inflation targeting: it is optimal to commit to a higher price level for some time once the ZLB will no longer be binding. However, unlike inflation targeting, a price-level target constrains the credible amount of overshooting through deflationary expectations when returning to target. So it may be optimal to commit to holding nominal rates at zero for an extended period even after the shock has abated. Again, optimal policy is not time consistent.

Under discretion, price-level targeting works indeed as automatic stabilization mechanism in the sense that it alleviates the "paradox of flexibility". Under inflation targeting, more flexible prices amplify contemporaneous deflation for a given contractionary shock. As shown in Werning (2012), discretionary welfare loss is lowest with completely rigid prices. In contrast, price-level targeting mitigates output shortfalls, during a deflationary liquidity trap, by raising inflationary expectations under discretion. In this regime, stronger contemporaneous deflation, due to more flexible prices, further increases inflationary expectations as long as long-run price expectations remain anchored. This decreases the real rate and stimulates consumption. We show that discretionary welfare loss is lowest with fully flexible prices. However, the effect of price rigidities on welfare may be non-monotonic: for large enough price stickiness, relaxing price stickiness marginally, may lead to higher welfare losses.

Characterizing optimal commitment policy, successful forward guidance depends on the credibility of "irresponsible" monetary easing (Krugman, 1998). We show that under price-level targeting a new constraint emerges that may restrain optimal commitment. Similar to inflation

\footnotetext{
${ }^{1}$ For a recent survey see Hatcher and Minford (2014).
} 
targeting, it is optimal to commit to excess inflation. However, we show that under price-level targeting, the credible amount of future overshooting that the central bank can announce, is constrained by the ZLB even after the shock has abated. The reason is straightforward: periods of overshooting need to be followed by deflation to return to target. The stronger the overshooting, the larger the degree of deflation required later, driving the nominal policy rate possibly again to the ZLB. So the central bank may find it optimal to hold the nominal rate at zero for an extended period while postponing the return to the price level-target.

Recently, Cochrane (2013) argued that -due to nominal indeterminacy under inflation targetingthe New Keynesian framework exhibits multiple equilibria with different price paths, some of them with mild inflation and no output loss during a liquidity trap. We characterize the optimal price path under price-level targeting and show that price stickiness eliminates price-level indeterminacy under optimal policy.

Finally, we introduce government spending as additional policy tool. We show that, similar to inflation targeting, with price-level targeting, a countercyclical impact reaction of fiscal spending is optimal, both under discretion and commitment. When policy rates are zero for an extended period of time, government spending should become more front-loaded. However, since fiscal spending affects nominal rates through marginal utility, the credibility of an announced government spending path might be constrained by the ZLB even after the adverse shock fully abated. Finally, we show that procyclical fiscal policy always results in welfare losses that are even higher than under discretionary policy.

The reminder of the paper is organized as follows: Section 2 outlines our model. Section 3 analyzes discretionary monetary policy and the role of price rigidities on welfare losses. Section 4 derives the optimal forward guidance paths. Section 5 introduces fiscal spending into our model and Section 6 concludes.

\section{Baseline Model}

We consider a discrete time, three-period setup with $t \in[1,2,3]$. The households' optimization problem is given by

$$
\begin{aligned}
& \underset{\left\{C_{t}, N_{t}\right\}_{t=1}^{3}}{\max } \mathbb{E}_{1}\left[\sum_{t=1}^{3}\left(\prod_{j=1}^{t-1} \frac{1}{1+\rho_{j}}\right)\left(\frac{C_{t}^{1-\frac{1}{\sigma}}}{1-\frac{1}{\sigma}}-\frac{N_{t}^{1+\varphi}}{1+\varphi}\right)\right] \\
& \text { s.t. } \\
& P_{1} C_{1}+B_{1}=W_{1} N_{1}+T_{1} \\
& P_{2} C_{2}+B_{2}=W_{2} N_{2}+\left(1+i_{1}^{S}\right) B_{1}+T_{2} \\
& P_{3} C_{3}=W_{3} N_{3}+\left(1+i_{2}^{S}\right) B_{2}+T_{3}
\end{aligned}
$$

where $\rho_{j}$ is the stochastic discount rate, $\sigma$ is the elasticity of inter-temporal substitution, $\varphi$ characterizes the elasticity of labor supply, $C_{t}$ is real consumption, $N_{t}$ are hours worked and $P_{t}$ is the price level. Households save via the purchase of short-term (one period) nominal bonds, $B_{t}$, which yield interest $i_{t}^{S}$. $W_{t}$ is the nominal wage rate and $T_{t}$ are nominal lump-sum 
net transfers including firms' profits and lump-sum taxes. It is straightforward to derive the log-linear aggregate-demand curves through the Euler equation and market clearing condition:

$$
\left.y_{t}-y^{\star}=\mathbb{E}_{t}\left[y_{t+1}-y^{\star}\right]-\sigma\left(i_{t}^{S}-\left[\mathbb{E}_{[} p_{t+1}\right]-p_{t}\right]-\rho_{t}\right), \quad t \in\{1,2\}
$$

where $y_{t} \equiv \log Y_{t}, p_{t} \equiv \log P_{t}$ and $y^{\star}$ denoting the efficient (log-)level of production.

Firms have mass one. Imposing the standard Calvo (1983) assumption induces inflation targeting as welfare-optimal policy. To see this, consider a Calvo mechanism in our three-period setup. Without loss of generality, assume that in period 0 the economy is in steady state and price dispersion is zero, such that the aggregate price level $p_{0}$ equals the idiosyncratically optimal price level $p_{0}^{\star}$. In period 1 an exogenous shock shifts the idiosyncratically optimal price level to $p_{1}^{\star} \neq p_{0}^{\star}$. Let $\Gamma \in(0,1)$ denote the Calvo probability that a firm is able to just prices. Then, coming from a steady state, in period 1 the aggregate price level is given by $p_{1}=(1-\Gamma) p_{0}^{\star}+\Gamma p_{1}^{\star}$. The central bank, which can control aggregate demand perfectly, is concerned with welfare-detrimental idiosyncratic price dispersion resulting in inefficient labor allocation. In period 2 the central bank's problem therefore is to minimize price dispersion by setting $p_{2}^{\star}$ optimally. Given the Calvo assumption, in period 2 the mass of firms charging $p_{0}^{\star}$ is $\mathcal{M}_{0}=(1-\Gamma)^{2}$, the mass of firms charging $p_{1}^{\star}$ is $\mathcal{M}_{1}=\Gamma(1-\Gamma)$ and the mass of firms that will be charging $p_{2}^{\star}$ is $\mathcal{M}_{2}=\Gamma^{2}+(1-\Gamma) \Gamma=\Gamma$. Therefore, the aggregate price level in period 2 is $p_{2}=\mathcal{M}_{0} p_{0}^{\star}+\mathcal{M}_{1} p_{1}^{\star}+\mathcal{M}_{2} p_{2}^{\star}$. Idiosyncratic price dispersion is given by $\mathcal{D}_{2}=\operatorname{var}_{i}\left(p_{2}(i)\right)=\sum_{t=0}^{2} \mathcal{M}_{t}\left[p_{t}^{\star}-p_{t}\right]^{2}$. Minimizing $\mathcal{D}_{2}$ by choosing $p_{2}^{\star}$ implies $p_{2}^{\star}=p_{1}$ and given the Calvo inflation process it follows that $p_{2}=p_{1}$, such that $\pi_{2}=0$. It is straightforward to apply this argument to any period $t$. Therefore, with Calvo mechanism, minimizing idiosyncratic price dispersion induces an aggregate inflation target of zero.

The intuition for this result is as follows: with Calvo-pricing firms are homogeneous ex-ante (before it is exogenously determined which firms can adjust prices). Therefore, in response to an exogenous shock, all firms want to adjust to the same new optimal price. In that sense, the adjusting firms are representative for idiosyncratic optimal behavior of all firms. Consequently, with Calvo-pricing, inflation is a perfect signal of idiosyncratic price distortions, because inflation only occurs if the adjusting firms find a new price level optimal. ${ }^{2}$ But as the non-adjusting firms find the same price level optimal, it necessarily follows that these firm cannot behave optimally and price distortions emerge. Therefore, with Calvo-pricing, targeting a zero rate of inflation emerges as the natural strategy for a central bank that is concerned with minimizing price distortions.

To modify the framework such that price-level targeting emerges endogenously as welfareoptimal policy, we do not impose a Calvo mechanism, but allow firms to be ex-ante heterogeneous. In particular, a share $\alpha_{1}$ exhibits long-run price stickiness and a share $\alpha_{2}$ exhibits short-run price stickiness. Assume that in the past (call it period 0), the economy has been in steady state such that all firms charged the same price $p^{\star}$. $\alpha_{1}$-type firms have long-run sticky prices in the sense that they cannot deviate from $p^{\star}$ in periods 1, 2 and, with probability $\lambda$, also not in period 3. The parameter $\lambda$ allows us to vary the degree of long-run rigidity in period 3 independent of rigidities in the other periods. A share $\alpha_{2}$ of firms exhibits short-run price stickiness, because they cannot deviate from $p^{\star}$ only in period 1, but can adjust freely from

\footnotetext{
${ }^{2}$ Only with perfectly flexible prices, inflation is no signal for price distortions.
} 
then on. The remaining $1-\left(\alpha_{1}+\alpha_{2}\right)$ firms can adjust their prices freely also in period 1 . In contrast to Calvo pricing, where both short-run and long-run stickiness are controlled by the Calvo-parameter only, this pricing scheme allows us to elaborate on the (potentially asymmetric) effects of short-run and long-run price stickiness on optimal monetary policy commitment. ${ }^{3}$

Firms' production technology is homogeneous and given by $Y_{t}(i)=A N_{t}(i), \forall i \in[0,1]$, where $A$ is a productivity constant. The good market is monopolistic competitive such that $Y_{t}(i)=\left(P_{t}(i) / P_{t}\right)^{-\theta} Y_{t}$ with $\theta$ being the elasticity of substitution between a continuum of goods. Given our pricing scheme aggregate (log-) supply can be derived as

$$
p_{t}-p^{\star}=\kappa_{t}\left[y_{t}-y^{\star}\right], \quad t \in\{1,2,3\}
$$

where $\kappa_{1}=\frac{1-\alpha_{1}-\alpha_{2}}{\alpha_{1}+\alpha_{2}}\left(\frac{1}{\sigma}+\varphi\right), \kappa_{2}=\frac{1-\alpha_{1}}{\alpha_{1}}\left(\frac{1}{\sigma}+\varphi\right)$ and $\kappa_{3}=\frac{1-\alpha_{1} \lambda}{\alpha_{1} \lambda}\left(\frac{1}{\sigma}+\varphi\right)$. Since $\lim _{\alpha_{1} \rightarrow 0} \kappa_{2}=$ $\lim _{\alpha_{1} \rightarrow 0} \kappa_{3}=+\infty$ but $\lim _{\alpha_{1} \rightarrow 0} \kappa_{1} \neq+\infty$ there will be no output gaps in period 2 and 3 if long-run price rigidity is zero. In period 1 , however, an output gap emerges independently of $\alpha_{1}$ since also the $\alpha_{2}$-type firms have their period 1 prices set to $p^{\star}$ (short-term price rigidity). By construction, once some new firms are allowed to optimize freely under our pricing scheme ( $\alpha_{2}$ in period 2, $(1-\lambda) \alpha_{1}$ in period 3), they know that they are free to adjust from then on for all remaining periods. Therefore, unlike with a Calvo mechanism, when optimizing, firms do not need to internalize that they may not be allowed to re-optimize in the future. Thus, the aggregate supply curve is determined by the nominal anchor $p^{\star}$, from which some firms will never deviate. Thus, if $y_{t}$ deviates from its equilibrium level, firms that can adjust prices freely will opt for a different price than $p^{\star}$, inducing welfare losses through inefficient labor allocation. So a price-level target of $p^{\star}$ emerges endogenously as welfare-optimal policy in the welfare function. Using a second-order Taylor approximation of the utility function, the welfare-loss function can be derived as

$$
\mathcal{L}_{1}=\frac{1}{2} \mathbb{E}_{1}\left[\sum_{t=1}^{3}\left(\prod_{j=1}^{t-1} \frac{1}{1+\rho_{j}}\right)\left\{\left(y_{t}-y^{\star}\right)^{2}+\frac{\theta}{\kappa_{t}}\left(p_{t}-p^{\star}\right)^{2}\right\}\right] .
$$

Monetary policy is characterized by the announcement of price path $\left\{p_{t}\right\}_{t=1}^{3}$ to forward guide expectations. The central bank's objective is to minimize the quadratic loss function subject to the aggregate demand curves, Equation (2.1) and aggregate supply curves, Equation (2.2). According to Equation (2.3) the central bank would like to close the price gap $p_{t}-p^{\star}$ in every period. This can always be implemented if monetary policy is contemporaneously not constrained by the ZLB, i.e. if the nominal rate $i_{t}^{S}$ that induces $p_{t}-p^{\star}=0$, is positive. This incentive holds irrespectively of any history $\{0,1, \ldots, t-1\}$ since Equations $(2.1)$ and $(2.2)$ only include contemporaneous and forward-looking variables. This gives rise to a dynamic inconsistency problem.

For the simulation exercises in Section 4 and 5 we choose a standard calibration with $A=$ $1, \beta=0.99, \sigma=\varphi=1$ and $\theta=5$ (= $25 \%$ markup). We choose $\alpha_{2}$ to be small to allow for high $\alpha_{1}$ when $\alpha_{1} \rightarrow 1-\alpha_{2}: \alpha_{2}=0.1 .4$ For the baseline calibration, we choose $\alpha_{1}=0.25$,

\footnotetext{
${ }^{3}$ Using a three-period model keeps this price scheme analytically traceable, as it limits the accumulation of price dispersion over time.

${ }^{4}$ The calibration of $\alpha_{2} \in\left[0,1-\alpha_{1}\right]$ has no qualitative effects on our results.
} 
such that in period $135 \%$ of firms cannot adjust their prices. We set $\lambda=1$. The effects of different calibrations of $\alpha_{1}$ and $\lambda$ will be discussed in the following sections. When introducing government spending, we assume that in efficient equilibrium $G^{\star} / Y^{\star}=0.2$ and the inverse intertemporal elasticity of substitution of government spending $\eta_{g}=1$.

\section{Discretionary Policy}

To provide the simplest framework for our liquidity trap analysis, we consider the following thought experiment: before period 1 the economy is in its steady state with price at target and output gap closed. The central bank is expected to keep prices at target also in the future: $\mathbb{E}_{0}\left[p_{t}\right]=p^{\star}, t \in\{1,2,3\}$. Following Eggertsson (2006) we assume that in period 1 a negative time preference shock, $\rho_{1}$, with $\rho_{1}<0<\bar{\rho}=\rho_{2}$, hits the economy and drives it to the zero lower bound. To keep the exercise traceable, we assume that there is no persistence in the shock, such that, without any policy responses, the economy will revert back to steady state in period 2 . Thus, in our setup the ZLB will be binding for one period only. Solely by cutting the interest rate down to zero, the central bank cannot prevent a recession in period 1, since this would require a negative nominal rate. It can, however, announce to raise the price levels in the following periods above target $p^{\star}$ to lower the current real rate of interest and thus to stimulate current consumption even when the nominal policy rate remains stuck at zero. To perfectly stabilize the economy in the first period the central bank would need to credibly announce a price level of $\bar{p}_{2}=p^{\star}+\left|\rho_{1}\right|$ for period 2. Such a policy, however, will never be optimal commitment strategy: raising $p_{2}$ above $p^{\star}$ causes inefficiencies and thus welfare loss next period. The optimal commitment strategy is to promise to raise $p_{2}$ only so much that the marginal loss in period 2 (from accepting a price $p_{2}>p^{\star}$ ) will be just equal to the marginal gains in period 1 (from preventing $p_{1}$ to fall too far below $p^{\star}$ ).

Before we turn to the derivation of the optimal commitment strategy, we first establish a result under discretion that is in stark contrast to a standard inflation-targeting regime. Werning (2012) shows in his Proposition 2 for a continuous time model with inflation targeting that welfare losses under discretion are lowest when prices are fully rigid (see also Eggertsson and Krugman, 2012). Although this results may seem counter-intuitive as price rigidity is a friction, it is an intrinsic feature of inflation targeting. Assume that a contractionary shock drives the economy on impact to the ZLB and it is known to remain there for one period only. The shock depresses output and thus deflation emerges. Given that inflation expectations are well anchored at inflation target $\pi^{\star} \geq 0$, the real rate is given according to the Fisher equation by $r=-\mathbb{E} \pi=-\pi^{\star}$. Therefore, the real rate is affected neither by the strength of contemporaneous deflation nor the degree of price stickiness. If price rigidity is increased, onimpact deflation is mitigated, as prices can respond less to the shock, while output is further depressed through price-induced, demand effects. Werning (2012) proves that the welfareimproving effect dominates, such that discretionary welfare losses are lower, the more rigid prices are. $^{5}$

\footnotetext{
${ }^{5}$ We assume the ZLB to be binding for one period only. But the result remains unaffected if it is binding for multiple periods. However, in that case the slope of the $\mathrm{AD}$-curve is key: under inflation targeting, the economy jumps to the upward sloping part of the $\mathrm{AD}$-curve, whereas under price-level targeting it remains at
} 
In contrast, price-level targeting features an automatic stabilization mechanism through the real rate, as inflation expectations are not constant under anchored price-level expectations. Under discretion the central bank implements $P_{t}=P^{\star}$ once the ZLB stops binding. Therefore, the stronger the deflation (undershooting) during the liquidity trap period, the higher is the rationally anticipated inflation that leads the economy back to target. This reduces the real interest rate and hence output shortfalls. Consequently, the lower price stickiness, the stronger is deflation induced by the adverse ZLB-shock. While this creates additional welfare losses through price deviations, output deviations are reduced. For the limiting cases of perfect flexibility and perfect stickiness, the positive output effect dominates the negative price effect, because - as under inflation targeting - the weight on price deviations approaches zero for fully flexible prices (see Equation (2.3)). ${ }^{6}$ Discretionary price and output gap are given by $\left(y_{1}^{D}-y^{\star}\right)=\frac{\sigma}{1+\kappa_{1} \sigma} \rho_{1}$ and $\left(p_{1}^{D}-p^{\star}\right)=\frac{\sigma \kappa_{1}}{1+\kappa_{1} \sigma} \rho_{1}$, respectively. Then, the discretionary welfare loss is $\mathcal{L}_{1}^{D}=\frac{1}{2} \frac{1+\theta \kappa_{1}}{\left(1+\sigma \kappa_{1}\right)^{2}}\left(\sigma \rho_{1}\right)^{2}$. Let $\alpha=\alpha_{1}+\alpha_{2}$ be the fraction of sticky prices in period 1. Since $\lim _{\alpha \rightarrow 0} \kappa_{1} \rightarrow \infty$ and $\lim _{\alpha \rightarrow 1} \kappa_{1} \rightarrow 0$ it follows that

$$
\lim _{\alpha \rightarrow 0} \mathcal{L}_{1}^{D}=0<\lim _{\alpha \rightarrow 1} \mathcal{L}_{1}^{D}=\frac{1}{2}\left(\sigma \rho_{1}\right)^{2}
$$

Consequently, the paradox of flexibility does not emerge under price-level targeting. Even under discretion, undershooting the price-level target credibly triggers higher inflation expectation, such that welfare losses due to deflation are attenuated by a reduction in the real interest rate (see also Eggertsson and Woodford, 2003).

Interestingly, for certain parameter calibration, the effect of price rigidity on aggregate welfare is non-monotonic. As shown in Figure 1, the maximum welfare loss is reached at $\bar{\alpha}=\frac{1+\sigma \varphi}{2\left(1-\frac{\sigma}{\theta}\right)+\sigma \phi}$. The location of that turning point is determined by the intratemporal elasticity of substitution, $\theta$ relative to intertemporal elasticity of substitution, $\sigma$. The higher the degree of inter-firm competition the more left-skewed becomes the welfare-loss function. $\bar{\alpha}$ move towards zero in the unit interval, i.e. a lower degree of price rigidity induces the maximum welfare loss, while welfare loss at the limiting cases remains unaffected by $\alpha$, as shown in Equation (3.1). The intuition is the following: Equation (2.3) shows that higher competition increases the welfare-weight of price deviations and therefore, ceteris paribus, discretionary welfare loss. If firm competition is strong, i.e. intra-temporal elasticity of substitution is high, the effect of price dispersion on demand for goods is strong. The same price differential induces a stronger demand shift towards cheaper goods. Consequently, for constant degree of price rigidity, production choice and labor allocation become stronger distorted and aggregate welfare decreases. For $\bar{\alpha}<1 \Leftrightarrow 2 \sigma<\theta$, i.e. inter-firm competition is strong enough, aggregate welfare loss increases in $\alpha$ for $\alpha \leq \bar{\alpha}$ but decreases for $\alpha>\bar{\alpha}$. The intuition behind this non-monotonicity is as follows:

1. An increase in price rigidity, $\alpha$, makes the AS-curve flatter increasing output volatility for given price deviations $p_{1}^{D}-p^{\star}$. This induces higher welfare losses.

the downward sloping part. In the first case, inflation and output gap are positively correlated, while in the second case the correlation is negative. Therefore, our results can be extended to the multi-period case, since on a downward sloping $\mathrm{AD}$-curve deflation reduces output shortfall. We are grateful to an anonymous referee for pointing this out to us.

${ }^{6}$ Under inflation targeting and Calvo-pricing, the positive effect of price rigidity dominates its negative effect through higher welfare weights. This is shown in Werning (2012), proposition 2. 
2. In contrast, an increase in $\alpha$ reduces price volatility, which improves welfare.

3. However, an increase in $\alpha$ also raises the weight, $\theta / \kappa_{1}$, of price deviations in the welfare loss function (see Equation (2.3)). ${ }^{7}$

For $\alpha \in[0, \sigma /(1+\sigma)]$ the third effect dominates the second effect since the increase of the welfare weight is initially stronger in $\alpha$ than the reduction in price volatility. Therefore, for $\alpha$ low enough, the first and the aggregate effect of 2. and 3. work into the same direction and welfare losses rise in $\alpha$. However, the second effect is more convex than the third effect and thus the more $\alpha$ increases the stronger becomes the former relative to the latter (at $\alpha=\sigma /(1+\sigma)$ both effects are equal). For $\alpha>\sigma /(1+\sigma)$ the aggregate welfare effect of 2 . and 3 . turns positive, attenuating the negative effect of higher output volatility. Since for further increases in $\alpha$ the aggregate positive effect $(2 .+3$.) on welfare is more convex than the negative effect (1.) the former effect gradually catches up and at $\alpha=\bar{\alpha}$ the total effect of price rigidity on welfare starts turning positive.

Therefore, while the picture for the two extreme cases $(\alpha=0 \wedge \alpha=1)$ is clear-cut, the marginal effect of price rigidity on welfare depends on $\bar{\alpha}$. Only for $\bar{\alpha} \geq 1$ a marginal decrease in price rigidity is always welfare-improving in our model.

Figure 1: Price Rigidities and Welfare Loss

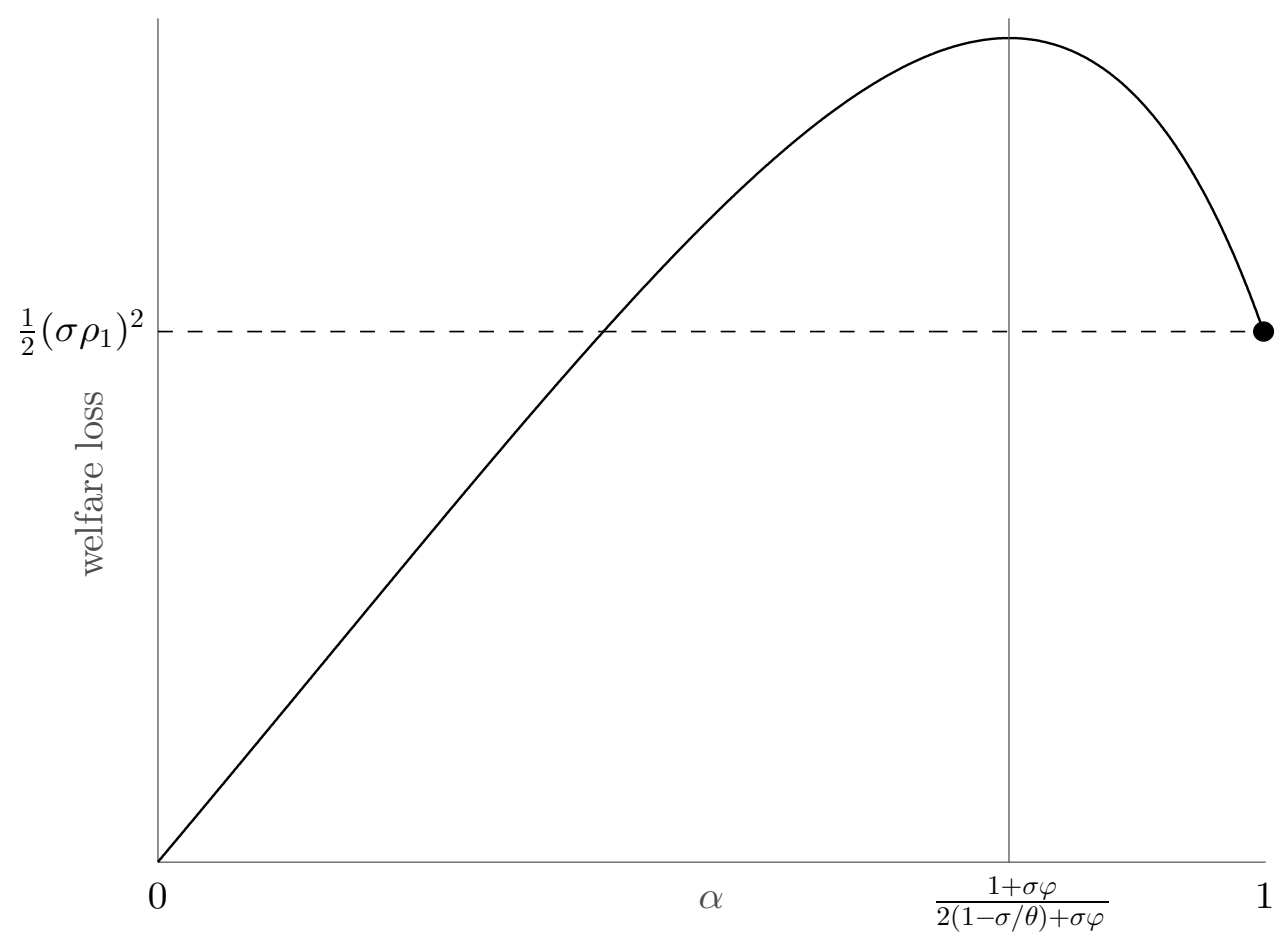

${ }^{7}$ Note that the weight on output deviations is normalized to unity. 


\section{Optimal commitment policy}

It is well understood that to obtain optimal stabilization, the announced price path needs to be credible. Forward guidance suffers from a dynamic inconsistency problem (Barro and Gordon, 1983): if the ex-ante announcement of the future price-level path is successful in mitigating the ZLB, ex-post the central bank has no incentive to stick to its promises but rather wants to return to the price level target to minimize contemporaneous and future welfare $\operatorname{losses}^{8}$ To analyze optimal commitment policy, we assume that central bank announcements are perfectly credible according to the following assumption:

Assumption 1. Feasible policy announcements $x_{t+i}^{a}, i \in \mathbb{N}$, about a variable $x_{t}$ are credible in the sense that

$$
\mathbb{E}_{t}\left[x_{t+i}\right]=x_{t+i}^{a}, i \in \mathbb{N}
$$

This assumption is no purely theoretical concept. Figure 2 provides suggestive evidence for credible commitment of the US Fed, that engaged early into explicit forward guidance. The solid line indicates the effective policy rate for the US as estimated by $\mathrm{Wu}$ and Xia (2014), adjusting the actual rate for unconventional policy measures. The vertical line indicates March 2009, the first time the Fed announced "exceptionally low levels of the federal funds rate for an extended period." While other unconventional measures have also contributed to driving the effective policy rate further down, the Fed's forward guiding announcements since early 2009 have been a key factor (Campell, Evans, Fisher, Justiniano, Calomiris, and Woodford, 2012). Therefore, provided a central bank has sufficient credibility, forward guidance -combined with other unconventional policy measures-can contribute successfully to mitigating the problem of the ZLB successfully.

Figure 2: Forward Guidance in the US

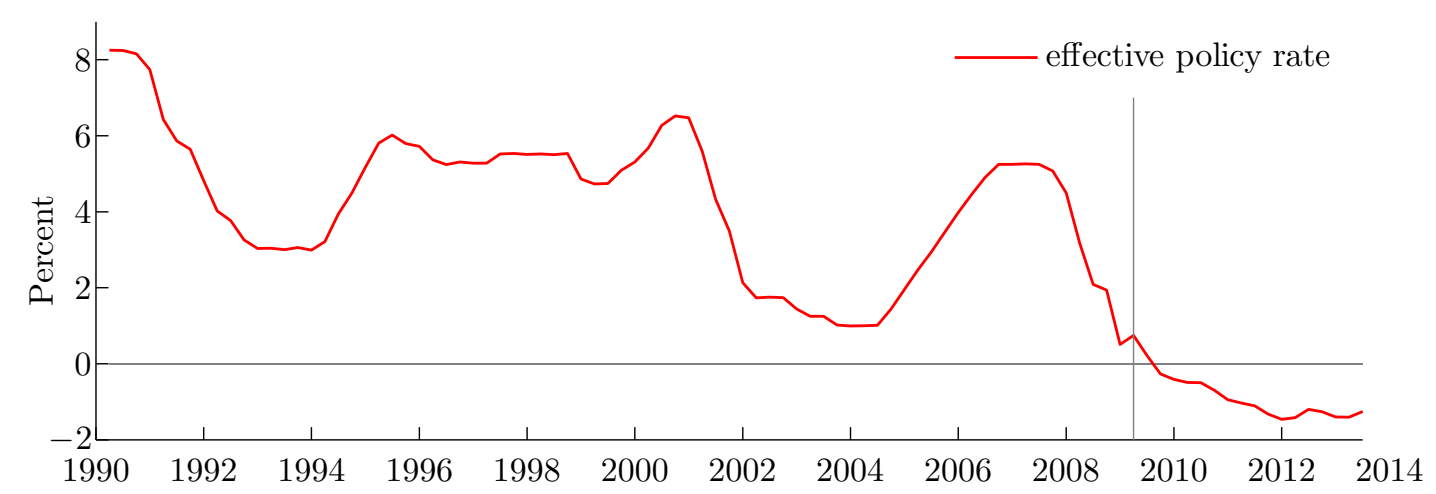

Notes: The time series for the effective policy rate is taken from Wu and Xia (2014). The vertical line indicates March 2009, the first time when the Fed announced "exceptionally low levels of the federal funds rate for an extended period."

To derive the optimal price path under forward guidance, from now on we assume that forward guidance is fully credible according to Assumption 1. The central bank is assumed

\footnotetext{
${ }^{8}$ For a discussion of dynamic inconsistency problem in forward guidance see for example Woodford (2003).
} 
to be able to guide the aggregate price level perfectly through announcements. ${ }^{9}$ To solve for optimal policy in a liquidity trap we minimize Equation (2.3) s.t. Equations (2.1) and (2.2), Assumption 1 and $i_{1}^{S}=0$. The solution is given by

$$
\begin{aligned}
& 0= \frac{1+\theta \kappa_{1}}{\kappa_{1}^{2}}\left(p_{1}-p^{\star}\right)+\frac{1}{1+\rho_{1}} \frac{\left(1+\theta \kappa_{2}\right)\left(1+\kappa_{1} \sigma\right)}{\kappa_{1} \kappa_{2}\left(1+\kappa_{2} \sigma\right)}\left(p_{2}-p^{\star}\right)+\ldots \\
& \cdots+\frac{1}{1+\rho_{1}} \frac{1}{1+\bar{\rho}} \frac{\left(1+\theta \kappa_{3}\right)\left(1+\kappa_{1} \sigma\right)}{\kappa_{1} \kappa_{3}\left(1+\kappa_{3} \sigma\right)}\left(p_{3}-p^{\star}\right), \\
& p_{1}-p^{\star}=\frac{\kappa_{1}\left(1+\kappa_{2} \sigma\right)}{\kappa_{2}\left(1+\kappa_{1} \sigma\right)}\left(p_{2}-p^{\star}\right)+\frac{\kappa_{1} \sigma}{1+\kappa_{1} \sigma} \rho_{1}, \\
& i_{2}^{S}=\bar{\rho}+\frac{1+\kappa_{3} \sigma}{\kappa_{3} \sigma}\left(p_{3}-p^{\star}\right)-\frac{1+\kappa_{2} \sigma}{\kappa_{2} \sigma}\left(p_{2}-p^{\star}\right)
\end{aligned}
$$

The first equation of (4.1) requires optimal policy to equalize marginal welfare losses across time. Thereby, monetary policy is constrained by the remaining equations. Since the ZLB is binding in period 1, i.e. $i_{1}^{S}=0$, there will be positive co-movement between $p_{1}$ and $p_{2}$, as a higher $p_{2}$ increases inflation between these periods and thus lowers the real rate which stimulates demand in period 1. This is shown in the second equation of (4.1). The short-term nominal rate between periods 2 and $3, i_{2}^{S}$, is not necessarily zero as shown in the third equation of (4.1).

The optimal commitment under a price-level-targeting regime follows the intuition for inflation targeting (see Krugman, 1998) closely. In period 1, a discount factor shock disturbs the economy, driving the natural rate below zero. With the ZLB restricting the short-term policy rate, a recession is triggered. While under discretion the economy reverts back to steady state in period 2, optimal policy dampens period 1 recession by promising overshooting (excess inflation) in period 2, forcing the real rate of interest in period 2 below its natural level $r_{2}^{n}=\bar{\rho}$. In contrast to inflation targeting, where the economy never returns to the old price path after the ZLB ceases binding, under price-level targeting and price stickiness the central bank tries to return to $p^{\star}$ in period 3. This requires deflation between period 2 and 3 . To be able to orchestrate a boom in period 2 , the real rate must be lowered below its natural level, despite these deflationary expectations. Since agents have rational expectations, the real rate of interest is determined by the Fisher equation. Thus, under credible price-level guidance the nominal rate has to adjust consistently to the announced price path to satisfy the Fisher equation and to implement the required real rate. This imposes a crucial constraint on credible forward guidance with a price-level-targeting regime: the central bank cannot promise to implement arbitrarily high deflation between periods 2 and 3 as this can require a negative nominal interest rate. This can be seen when rearranging the third equation of (4.1):

$$
i_{2}^{S} \geq 0 \Leftrightarrow p_{3}-p_{2} \geq \frac{\kappa_{3}-\kappa_{2}}{\kappa_{2}\left[1+\kappa_{3} \sigma\right]}\left[p_{2}-p^{\star}\right]-\frac{\kappa_{3} \sigma}{1+\kappa_{3} \sigma} \bar{\rho} \equiv \mathcal{B} \leq 0
$$

i.e. the maximum deviation of $p_{3}$ from $p_{2}$ is constraint below, depending on the AS-curve slopes and the price path announced for period 2. This restriction does not appear with inflation targeting, as excess inflation is not necessarily succeeded by deflation. In this respect, while

\footnotetext{
${ }^{9}$ Dropping the expectation operator, the expected price level in periods 2 and 3 is given by $p_{2}=\alpha_{1} p^{\star}+\left(1-\alpha_{1}\right) p_{2}^{\star}$ and $p_{3}=\alpha_{1} \lambda p^{\star}+\left(1-\alpha_{1} \lambda\right) p_{3}^{\star}$, respectively.
} 
credible price-level targeting attenuates adverse welfare effects under discretion, relative to inflation targeting, it can limit central banks' leeway to additional dampen deflation through forward guidance. For arbitrary $p_{2}-p^{\star}>0$ it holds that $\partial \mathcal{B} / \partial \alpha_{2}=0$ and $\partial \mathcal{B} / \partial \alpha_{1}>0$, i.e. the constraint on optimal forward guidance is solely dependent on long-run price rigidity and becomes more likely to bind, the more rigid prices are in the long run. To analyze how this constraint affects forward guidance policy, let us first assume that the shock in period $1, \rho_{1}$, is weak enough such that the ZLB will not be binding in period 2 .

Assumption 2a. The discount factor shock $\rho_{1}$ is small enough such that under optimal policy the $Z L B$ is not binding on $i_{2}^{S}$.

Under Assumption 2a and for $p_{3}=p^{\star}$ we can solve (4.1) for optimal policy analytically. ${ }^{10}$ As long as the ZLB is not binding in period 2 the optimal price target in period 3 is $p_{3}=p^{\star}$ for the following reason: as long as optimal policy is able to dampen the recession via excess inflation in period 2 only, there is no need to deviate in period 3 from the target $p^{\star}$. Any deviation in $t=3$ would simply lead to an offsetting adjustment in the unconstrained nominal rate $i_{2}^{S}$ according to the third equation in (4.1). Price deviations in $t=3$ can therefore not induce any real effects and would only lead additional welfare losses due to price distortions. Therefore, unconstrained optimal forward guidance implements $p_{3}=p^{\star}$. Figure 3 shows the optimal policy paths compared to the discretionary solution given the baseline parameter calibration and $\rho_{1}=-0.01$.

\footnotetext{
${ }^{10}$ Plugging the optimal commitment solution into of Equation (4.2), Assumption 2a is identical to $\left|\rho_{1}\right| \leq$ $\left(1+\frac{1}{1+\rho_{1}} \frac{1+\theta \kappa_{2}}{1+\theta \kappa_{1}}\left(\frac{1+\kappa_{1} \sigma}{1+\kappa_{2} \sigma}\right)^{2}\right) \bar{\rho}$
} 
Figure 3: Optimal vs Discretion Policy
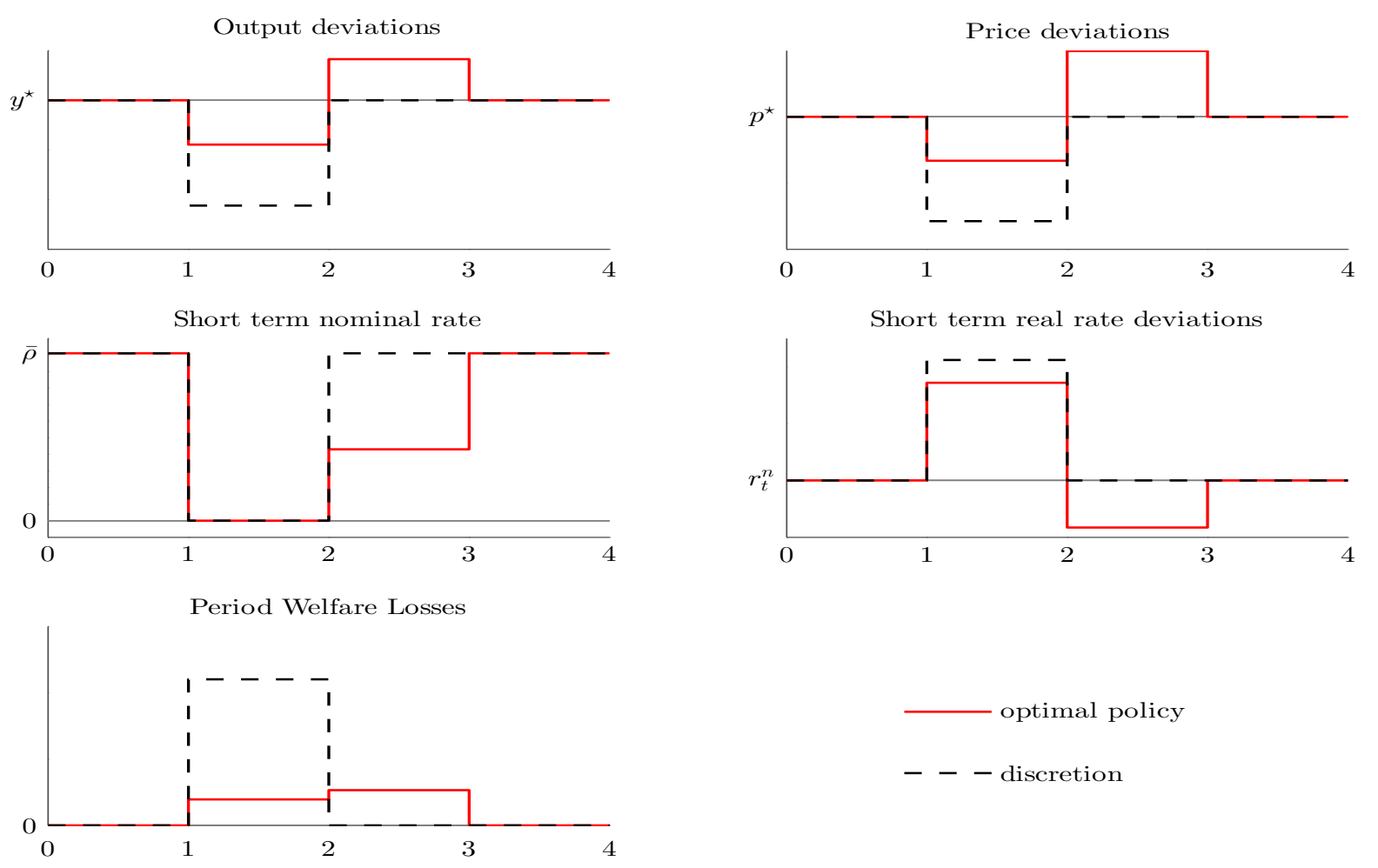

Notes: Unconstrained commitment solution for baseline calibration and $\rho_{1}=-0.01$ to ensure that the ZLB is not binding for $i_{2}^{S}$.

Optimal policy orchestrates a boom in period 2, which, additionally to the effects on inflation expectations, helps mitigating adverse ZLB effects through a reduction in expected marginal utility of consumption in $t=2$. This results is also documented for a inflation-targeting regime by Werning (2012). With $p_{3}=p^{\star}$ but $p_{2}>p^{\star}$ optimal unconstrained policy triggers deflationary expectations between periods 2 and 3 . If the discount factor shock is large enough, optimal policy might be constraint be the ZLB even after the shock has fully abated, as shown in Figure 4 for $\rho_{1}=-0.02$ and different degrees of long-run price stickiness.

The lower the degree of price stickiness, the higher the overshooting the central bank aims to implement in period 2. The transmission mechanism is straightforward: the lower the degree of price stickiness, i.e. the smaller the fraction of firms that fixed their prices at $p^{\star}$, the lower the weight of price deviations on welfare losses for $t=2,3 .{ }^{11}$ Therefore, price deviations from the target become less costly and monetary policy less eager to hit the target. However, as discussed above, not any overshooting can be credibly announced. As shown in the third panel of Figure 4, if long-run price rigidity is relatively low, policy would like to orchestrate a strong overshooting in period 2 as missing the target is less expansive in terms of welfare. But the thereby induced deflationary expectations from period 2 to 3 are strong enough to drive the nominal interest rate into negative territory. Thus, the announcement of theses price paths cannot be credible, as agents anticipate that the corresponding nominal rate violates the ZLB.

\footnotetext{
${ }^{11}$ Note that $\lim _{\alpha_{1} \rightarrow 0} \frac{\theta}{\kappa_{2}}=\lim _{\alpha_{1} \rightarrow 0} \frac{\theta}{\kappa_{3}}=0$.
} 
Figure 4: Effect of $\alpha_{1}$ on optimal policy
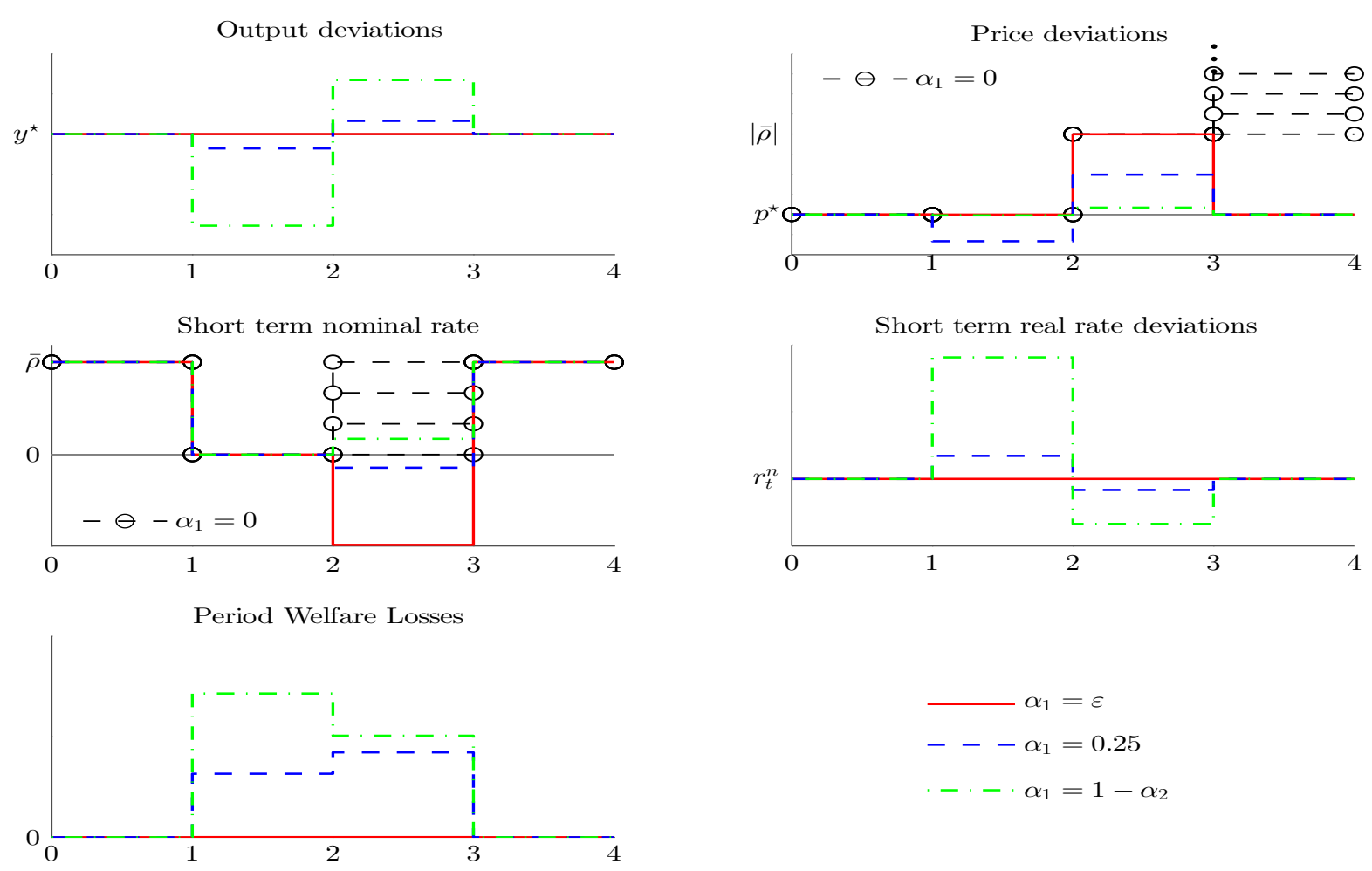

Notes: All parameters except $\alpha_{1}$ are kept at their baseline calibration and $\rho_{1}=-0.02$ to ensure that for $\alpha_{1}=0.25$ the ZLB is violated for $i_{2}^{S}$.

Under optimal commitment, aggregate welfare losses decrease monotonically in the degree of price stickiness. In particular, intertemporal losses approach zero if long-run price rigidity, $\alpha_{1}$, goes to zero. Therefore, the result establish in Equation (3.1) also holds with unconstrained forward guidance. With our pricing scheme, welfare losses, due to price deviations, occur because some firms find it optimal not to deviate from $p^{\star}$. If the fraction of these firms approaches zero, price deviations from target in period 2 become cheaper and in the limiting case monetary policy can stabilize period 1 perfectly by raising $p_{2}$ to $p^{\star}+\left|\rho_{1}\right|$. However, with marginal longrun price rigidity $\left(\alpha_{1}=\varepsilon\right)$, announcing this $p_{2}$ is not credible, as the corresponding deflation to $p_{3}=p^{\star}$ drives the nominal rate in period 2 below the ZLB (third panel in Figure 4). Only with perfectly flexible prices in period $3, \alpha_{1}=0$, perfect stabilization is credible, as in that case $p_{3}$ is indetermined. With prices being perfectly flexible, there is no longer a nominal anchor (dashed black lines in panels 2 and 3, Figure 4). In that case, the ZLB in period 2 is no longer a binding constraint, as $p_{3}$ can always be chosen such that $i_{2}^{S} \geq 0$. Therefore, the model features a discontinuity at $\alpha_{1}=0$. This discontinuity is independent of the degree of short-run price stickiness $\left(\alpha_{2}\right)$.

We now consider the case that the ZLB is a binding constraint also for period 2.

Assumption 2b. The discount factor shock $\rho_{1}$ is large enough and/or the degree of price stickiness is low such that under optimal policy the ZLB will be binding also in period 2, violating Assumption 2a. In that case $i_{2}^{S}=0$ 
The severity of the shock drives nominal rates to zero and thus restricts monetary authorities in implementing the optimal commitment price path. With the feasible amount of deflation between periods 2 and 3 being limited, policy is now restricted to be third best, requiring deviations from target also in period $3, p_{3}>p^{\star}$, to be able to credibly promise sufficient excess inflation in period 2.

Using $i_{2}^{S}=0$ in (4.1) allows us to solve for constrained optimal policy analytically. Figure 5 shows optimal policy with the ZLB being binding in period 2 compared to unconstrained optimal policy and the discretionary solution for $\rho_{1}=-0.05$. Under constrained optimal policy, forward guidance can provide less stimulation in period 1. The maximum downward jump in the price path from $t=2$ to $t=3$ is constrained by the ZLB on $i_{2}^{S}$ as the central bank cannot provide enough nominal ease to make any larger drop credible to agents. The drop in the price level required is so large that it drives $i_{2}^{S}$ far into negative territory. As agents anticipate that this is not feasible, the announced price path is thus not credible and the monetary authority can only implement the constrained best solution which induces higher aggregate welfare losses. Thus, third best policy has to keep the short-run nominal rate at the ZLB even after the shock has gone. Crucially, this is no direct consequence of the shock itself but of the optimal intertemporal trade-off between raising $p_{2}$ to attenuate the recession and the corresponding deflation between period 2 and $3 .^{12}$

\footnotetext{
${ }^{12}$ Whereas under unconstrained optimal policy the price path is decreasing between $t=2$ and $t=3$, this is not necessarily the case for constrained forward guidance. If period 1 and period 2 prices are very rigid $\left(\alpha_{1} \rightarrow 1-\alpha_{2}\right)$ but period 3 prices are very flexible, constrained optimal policy can mostly affects period 1 price expectations via period 3 announcements. The optimal price path is then increasing between periods 2 and 3 .
} 
Figure 5: Optimal Policy and the ZLB in period 2
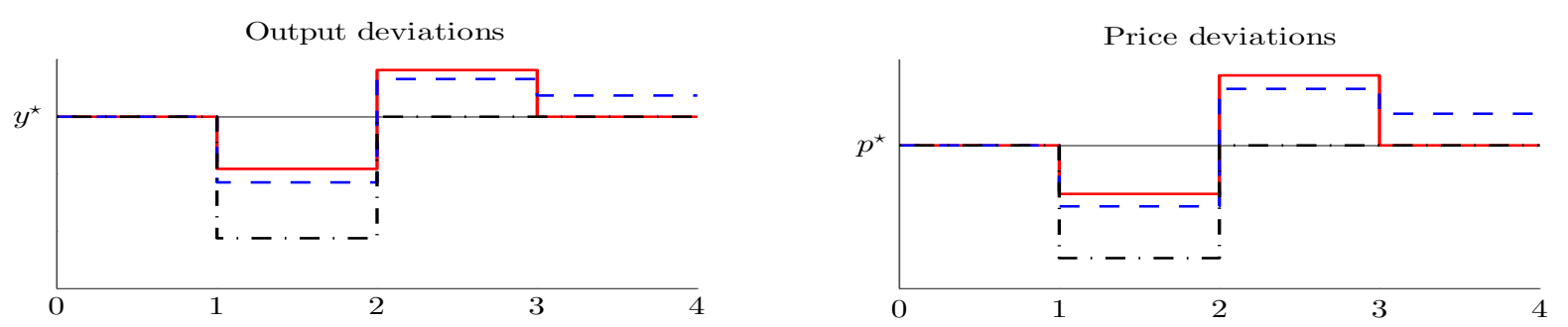

Short term nominal rate
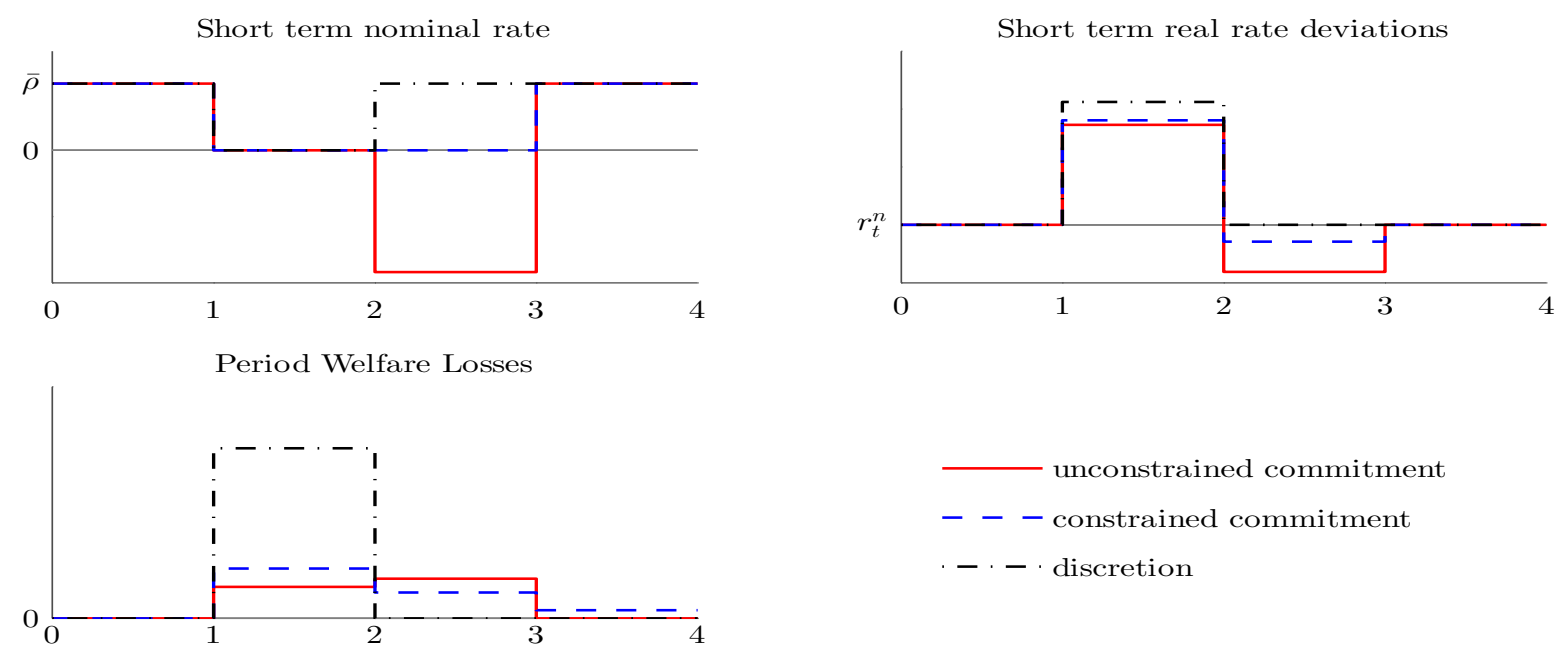

Notes: Constrained optimal solution for baseline calibration and $\rho_{1}=-0.05$ to ensure that the ZLB is binding for $i_{2}^{S}$.

The fact that under constrained optimal policy the economy does not return to target is driven by our three-period assumption. Extending our model to $n$ periods, for $n$ large enough the ZLB will at some point cease being a binding constraint as the deflation required for returning to target can be spread across sufficient periods. So, for large enough $n$, also constrained optimal policy will bring the price level back to target. However, also in this case the ZLB will be a binding constraint even after the shock has fully abated.

The effect of price stickiness on constrained optimal policy is similar to before. Again, the lower the degree of price stickiness in the model, the more excess inflation will be triggered under constrained forward guidance. For $\alpha_{1}=0$ the economy can be stabilized perfectly, without any welfare losses occurring over time as in that case the welfare weight on price deviations from period 2 on is zero. The higher $\alpha_{1}$ the less accommodative policy is and for $\alpha_{1}=1-\alpha_{2}$ barely any excess inflation will be announced. But due to a very flat AS-curve even these small deviations will be very costly as they imply strong output deviations.

On a more theoretical note, Cochrane (2013) recently argued that most results usually found in New Keynesian models during a liquidity trap are artifacts of an arbitrary equilibrium choice. To this end he introduces additional equilibria, identified by different steady state inflation rates that persist once the ZLB stops binding. These equilibria feature price paths that deviate arbitrarily from the old equilibrium path. Within our setup, it is straightforward to show that this results does not appear under price-level targeting. To this end, we introduce the 
degree of period -3 price rigidity $\lambda$. For $\lambda=0$ the price level in period 3 is perfectly flexible. Potential deviations from target in period 3 can be stronger, the lower $\lambda$, as the welfare weight of deviations approaches zero $\left(\lim _{\lambda \rightarrow 0} \frac{\theta}{\kappa_{3}}=0\right)$. Consequently, monetary policy can announce stronger overshooting for period 2 , given that it is optimal to let $p_{3}$ overshoot more strongly. But even for $\lambda$ close to zero no arbitrarily large price deviations in period 3 do occur as any deviation from $p^{\star}$ is costly. Under price-level targeting, (constrained) optimal policy determines $p_{3}$ uniquely. The price level $p_{3}$ will be indetermined only for $\lambda=0$. Hence, with only marginal price rigidities (constrained) optimal policy eliminates price level indeterminacy and thus does not support arbitrary equilibrium choice.

\section{Optimal Government Spending}

Up to now, policy could only stimulate during a zero interest rate environment by forward guiding expectations about the future price path. We now introduce government spending as an additional commitment device and analyze optimal fiscal policy in interaction with monetary policy and price level targeting. To this end, we follow Woodford (2011) and add additively separable government consumption to the household's utility function. Let $G_{t}$ denote the amount of a public good provided by the state and let $G^{\star}$ denote the corresponding steady state level. To keep this exercise as traceable as possible, we assume that government spending is financed via a lump-sum transfers $T_{t}$ and abstract from distortionary taxes. ${ }^{13}$ Although stylized, this setup allows us to take a stance on the cyclicality of optimal government spending in our discrete time model.

To see how government spending works in our model it is illustrative to consider the modified (log-linear) aggregate demand curve, derived from the Euler equation and market clearing condition $Y_{t}=C_{t}+G_{t}$ :

$$
y_{t}-y^{\star}=\mathbb{E}_{t}\left[y_{t+1}-y^{\star}\right]+\mathbb{E}_{t}\left[g_{t}-g_{t+1}\right]-\tilde{\sigma}\left[i_{t}^{S}-\rho_{t}-\mathbb{E}_{t}\left[\left(p_{t+1}-p^{\star}\right)-\left(p_{t}-p^{\star}\right)\right]\right]
$$

with $g_{t} \equiv \frac{G_{t}-G^{\star}}{Y^{\star}}$ and $\tilde{\sigma} \equiv \sigma\left(y^{\star}-g^{\star}\right), g^{\star}=\log \left(G^{\star}\right)$. To stimulate period $t$ production fiscal policy has two instruments at hand: first, it can raise $g_{t}$ to induce a direct demand effect on output and to make up for any private demand shortfall. Second, it can announce a decreasing government spending path between period $t$ and $t+1\left(g_{t}-\mathbb{E}_{t} g_{t+1}>0\right)$. This increases marginal utility of consumption of households in period $t$ relative to period $t+1$, as agents anticipate that future private consumption will be high due to less crowding-out. Hence, in addition to the announcement of a price level path, the credible commitment to some optimal path for government spending allows to attenuate the shock both directly and indirectly.

Given the time preference shock, it might seem optimal to cut government spending in the initial period in the same way as consumers cut current spending -after all, the social planner should internalize the time preference shock. With current real market rates being high, calling for austerity measures might be seen as the optimal response. But realizing that shadow rates are low, optimal policy will be characterized by intertemporal countercyclical spending shifts. It will be optimal to shift the path of fiscal policy relative to the optimal first best path by

\footnotetext{
${ }^{13}$ For a setup with distortionary taxes see for example Eggertsson (2006).
} 
raising government spending (lowering taxes) in the first (the liquidity trap) period relative to the second period (the period required to stimulate consumption by keeping the real rate below the natural rate). It pays to aim at positive (negative) additional spending during the period when the real rate is above (below) the natural rate, as long as the social planner realizes that this helps to bring the market rate closer to the shadow (natural) rate. Since even under commitment, it is never optimal for monetary policy to bring the real rate down to the natural rate during the liquidity trap period, additional instruments can always improve upon pure monetary policy. In that sense, macro "trumps" public finance.

Let us derive analytically the optimal government spending path under Assumptions 1-2 and $i_{1}^{S}=0$ for the baseline calibration. Under full commitment over both, the future price and government spending path, the joint monetary and fiscal authority now minimizes

$$
\begin{aligned}
& \mathcal{L}_{1}^{G}=\frac{1}{2} \mathbb{E}_{1}\left[\sum_{t=1}^{3}\left(\prod_{j=1}^{t-1} \frac{1}{1+\rho_{j}}\right)\left\{\varphi\left(y_{t}-y^{\star}\right)^{2}+\eta_{g} g_{t}^{2}+\eta_{u}\left(y_{t}-y^{\star}-g_{t}\right)^{2}+\frac{\theta(1+\varphi)}{\sigma \kappa_{t}}\left(p_{t}-p^{\star}\right)^{2}\right\}\right] \\
& \text { s.t. } \\
& p_{1}-p^{\star}=\frac{\kappa_{1}\left(\kappa_{2}+\tilde{\sigma}\right)}{\kappa_{2}\left(\kappa_{1}+\tilde{\sigma}\right)} \mathbb{E}_{1}\left[p_{2}-p^{\star}\right]+\frac{\kappa_{1}}{\kappa_{1}+\tilde{\sigma}}\left(g_{1}-\mathbb{E}_{1}\left[g_{2}\right]\right)-\frac{i_{1}^{S}-\rho_{1}}{\kappa_{1}+\tilde{\sigma}} \\
& p_{2}-p^{\star}=\frac{\kappa_{2}\left(\kappa_{3}+\tilde{\sigma}\right)}{\kappa_{3}\left(\kappa_{2}+\tilde{\sigma}\right)} \mathbb{E}_{2}\left[p_{3}-p^{\star}\right]+\frac{\kappa_{2}}{\kappa_{2}+\tilde{\sigma}}\left(g_{2}-\mathbb{E}_{2}\left[g_{3}\right]\right)-\frac{\kappa_{2} \tilde{\sigma}}{\kappa_{2}+\tilde{\sigma}}\left[i_{2}^{S}-\bar{\rho}\right]
\end{aligned}
$$

with $\eta_{u} \equiv \frac{1}{\sigma} \frac{Y^{\star}-G^{\star}}{Y^{\star}}$ and denoting the $\eta_{g}$ inverse intertemporal elasticity of substitution of the public good. Equation (5.2) is derived from a second order approximation of the extended utility function. ${ }^{14}$ Equations (5.3) and (5.4) represent the AS-AD equilibrium in periods 1 and 2, respectively, derived from Equations (2.2) and (5.1). The solution to this optimization problem is shown in Appendix A. Using these first-order-necessary conditions, one can derive the following relationship: $g_{1}=\Sigma_{1}\left[p_{1}-p^{\star}\right]$, with $\Sigma_{1}<0$ for any parameter calibration (see Equation (A.1)). Therefore, independent of commitment and the ZLB, optimal fiscal policy reacts countercyclical on impact. Thus, government consumption, which, unlike private consumption, can be perfectly adjusted by policy independently of the current market rate, is a tool to smooth output fluctuations by leaning against the wind.

Unconstrained optimal policy features a countercyclical government spending path with all variables returning to their equilibrium levels in $t=3$ (see solid line in Figure 6). The increase in government spending in period 1 makes up partially for the shortfall in private consumption and the credible commitment to relatively lower government spending in the future induces households to shift consumption again into period 1 via lower marginal utility in future periods. However, as above, implementing the unconstrained commitment path is feasible only as long as the nominal interest rate is non-negative in period 2. If, however, the adverse shock is large enough the ZLB will again be binding also in $t=2$. The reason can be seen in equation (5.4): given the optimal price level path, mitigating the ZLB might require $g_{2}-g_{3}$ to be positive, i.e. procyclical fiscal spending in period 2 or deviations from $g^{\star}$ in $t=3$. This cannot be optimal and hence government spending will not eliminate the possibility of a binding ZLB in period 2 in the presence of large shocks. In this case monetary policy is again limited in its ability to

\footnotetext{
${ }^{14}$ The derivation is available from the authors upon request.
} 
credible promise overshooting for $t=2$ (third panel in Figure 6), such that, as in Section 4, the drop from $p_{2}$ to $p_{3}$ is limited under constrained optimal policy (dashed line in Figure 6).

Figure 6: Optimal vs Discretionary Policy

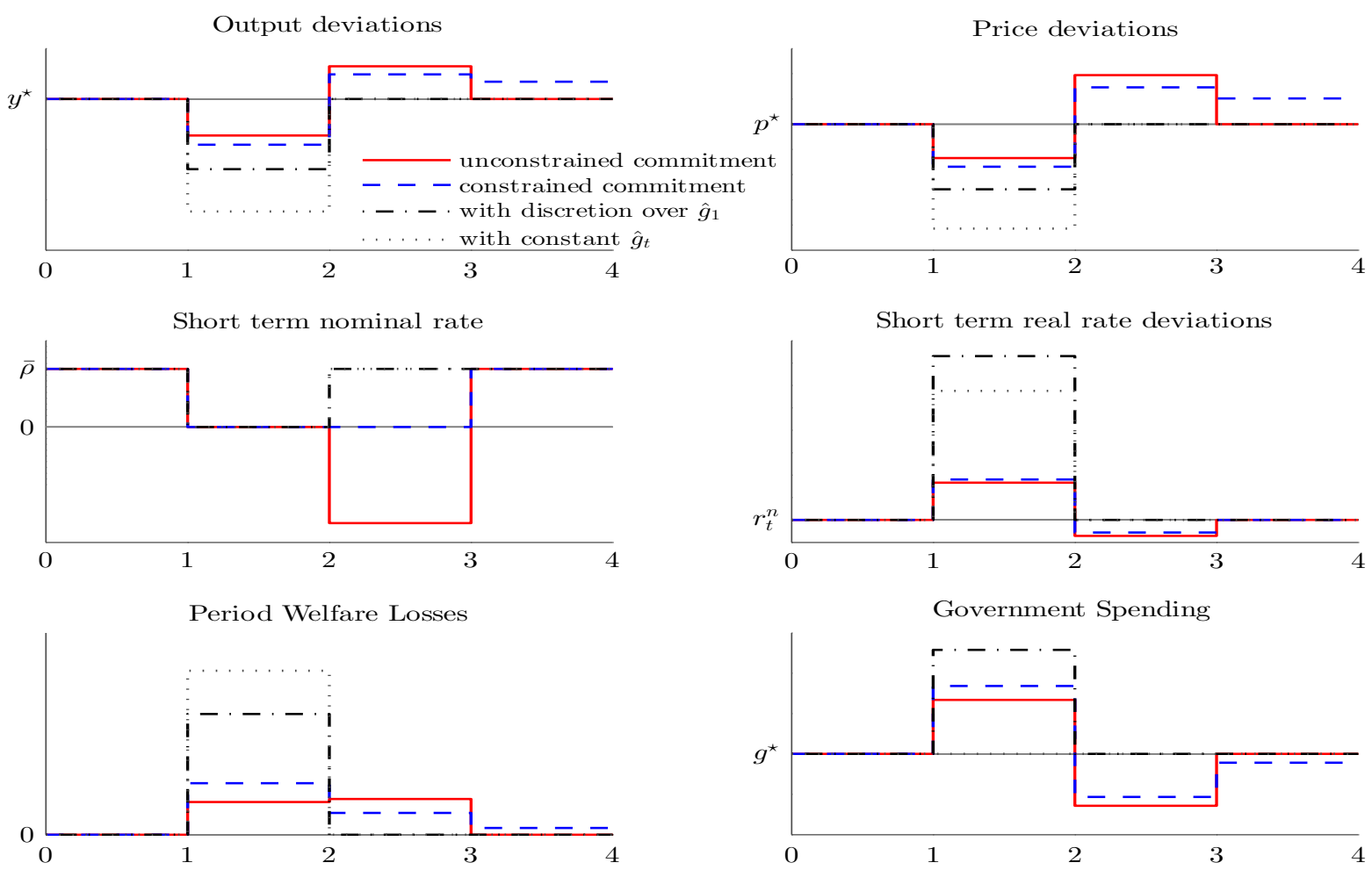

Notes: Parameters at baseline calibration. For this simulation $\rho_{1}=-0.05$.

However, government spending can partially make up for the short-fall of monetary policy by providing additional stimulus in the first period compared to the unconstrained solution. Note, however, that under constrained forward guidance the indirect stimulative effect of government spending, via low marginal utility of private consumption in the second period, is also constrained by the ZLB in $t=2$. Since, via Equation (5.4), $\partial i_{2}^{S} / \partial\left(g_{2}-g_{3}\right)>0$ an upward sloping government spending path between period 2 and 3 exhibits additional downward pressure on the nominal interest rate. Thus, the credible amount of future austerity that can be promised in $t=1$ is limited and $g_{3}$ has to deviate below $g^{\star}$ to allow for enough countercyclical spending in $t=2$. In that sense, under constrained optimal policy the short-run direct effect of countercyclical government spending is even more important. If the central bank keeps the policy rate at the ZLB for an extended period of time even after the shock abated, this should optimally be accompanied with stronger front-loaded countercyclical fiscal policy. Any short-fall in fiscal stimulus, e.g. due to procyclical austerity measures, will impose welfare costs onto the economy as we show below.

Let us finally turn to discretionary policies. We consider two different scenarios: first, we assume that monetary policy cannot commit to future activities and government spending is fully inactive (dotted line in Figure 6). Second, we assume that both monetary and fiscal 
cannot commit but that fiscal policy reacts optimally to the slump in period 1, for which no commitment is needed (ragged line in Figure 6). Clearly, without any commitment possible and hands of monetary policy being tied by the ZLB, fiscal policy can help to increase aggregate demand to attenuate the recession. The demand effect of increasing government spending and the deceasing government spending path offsets the slump partially even without any credible promise to future excess inflation.

During the recent crisis there have been calls for austerity spending even when policy rates are close to or at zero. To see the effects of such a policy we now analyze the case that the fiscal government, just like the household, takes the real rate as given and adjusts consumption accordingly, i.e. $G_{t}=C_{t} \forall t \in\{1,2,3\}$. Thus, with a high real rate at the ZLB, government consumption will be shifted into the future inducing a procyclical spending path and austerity. We assume that households and monetary policy are aware of this behavior and that monetary policy satisfies Assumption 1. In this case, forward guidance is again limited to the announcement of the future price level path.

The dashed lines in Figure 7 show optimal forward guidance given passive government behavior. For illustration, we consider the case of a small shock so that the ZLB is not binding in the second period. ${ }^{15}$ Government spending is now procyclical with high fiscal consumption when the real rate is low and vice versa. This policy turns out to be worse in terms of welfare than optimal unconstrained policy (solid line in Figure 7). The intuition is straightforward: procyclical government spending with austerity in the recession period amplifies economic fluctuations both through direct demand effects and via creating the incentive for households to further postpone consumption until period 2 when marginal utility is high.

Remarkably, procyclical fiscal policy also fares worse than the discretionary solution with active government spending in period 1 (ragged line in Figure 7). Since monetary policy internalizes the effects of its price level decisions onto government behavior, it is more reluctant to trigger a boom in $t=2$ as procyclical fiscal policy would amplify the output effects of excess inflation. Despite lower inflation in $t=2$ the real rate in period 1 drops sharply as output and prices deteriorate under procyclical fiscal spending. This partially dampens the drop in consumption and government spending. The recession in $t=1$ remains, however, severe. This, together with further fluctuations in periods 2 and 3 , induces higher aggregate welfare losses than under discretionary monetary and fiscal policy. In the latter case, losses in period 1 are high, but no additional losses occur in later periods. It is important to note that this result holds qualitatively independently of the calibration of $\eta_{u}$ and $\eta_{g}$ : it is independent of the weight of output and government spending fluctuations in the welfare loss function.

\footnotetext{
${ }^{15}$ The results are similar for a binding ZLB in $t=2$.
} 
Figure 7: Austerity policy
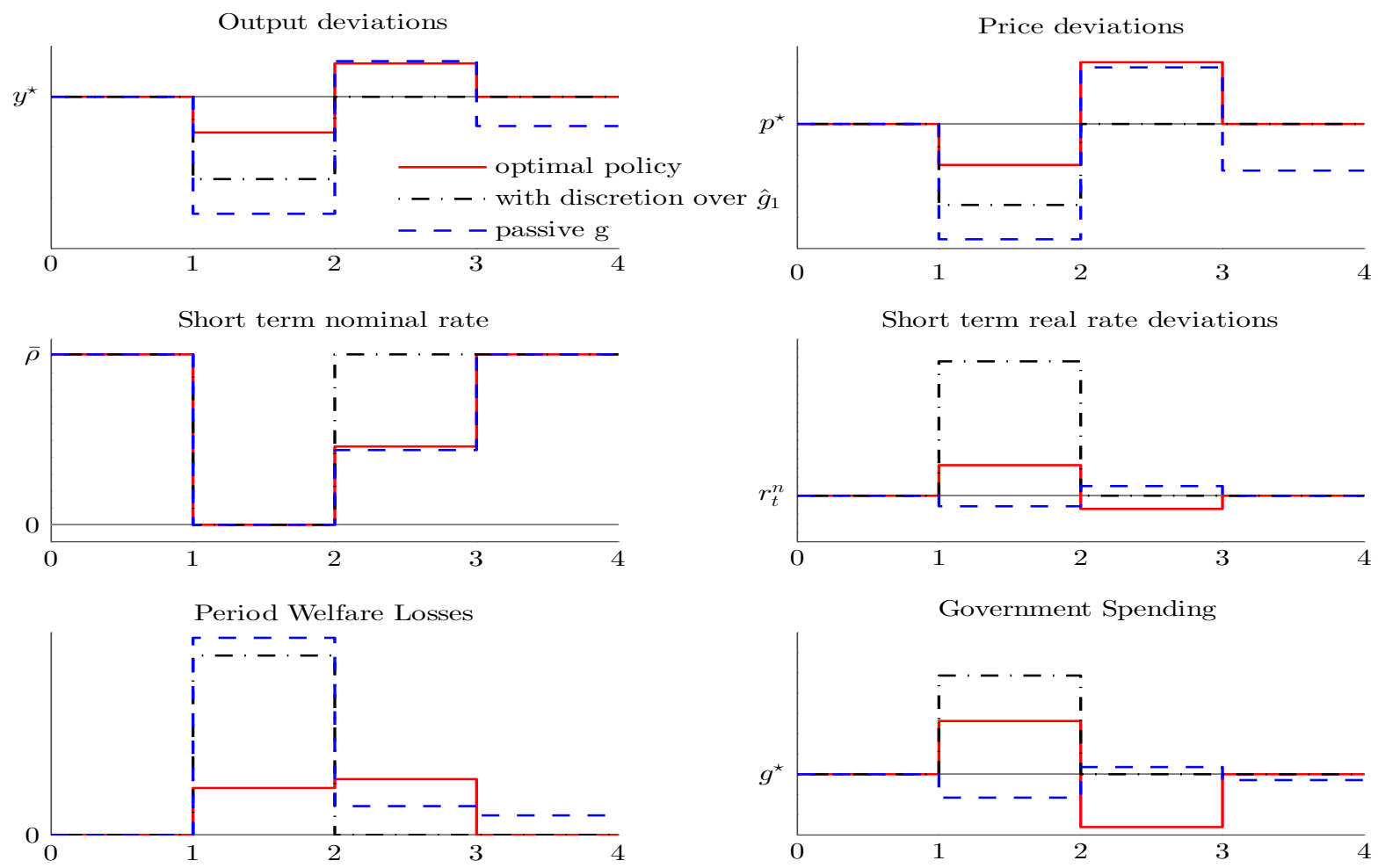

Notes: Parameters at baseline calibration. For this simulation $\rho_{1}=-0.01$.

\section{Conclusion}

Most results - as well as paradoxes- established for optimal monetary and fiscal policy at the ZLB, focus exclusively on the special case of Calvo pricing. This assumption induces inflation targeting as welfare-optimizing monetary policy, which makes forward guidance especially prone to the problem of dynamic inconsistency. We considered optimal policy under an alternative pricing scheme, where firms are ex-ante not perfectly identical, and showed that price-level targeting emerges endogenously as welfare-optimizing policy.

We establish four main results: First and in contrast to inflation targeting, under discretion a lower degree of price rigidity is welfare improving, as stronger deflation increases inflationary expectations. The paradox of flexibility, as identified by Werning (2012) and others, does not appear if the central bank targets the price level directly instead of its growth rate.

Second, under commitment price-level-targeting introduces a credibility constraint on pricepath announcements, that does not appear under inflation targeting. Through the Fisher equation, the nominal interest rate must be set consistently with the announced price path. Optimal policy needs to induce deflationary expectations between periods 2 and 3 . Therefore, the monetary authority faces a trade off between promising overshooting from period 1 to period 2 and the deflation required to bring the price level back to target in period 3. Consequently, the amount of excess inflation in period 2 may be constrained by the ZLB even after the shock has 
already faded away. This constraints the leeway of central bank forward guidance. Under inflation targeting, periods of excess inflation are not necessarily succeeded by periods of deflation. Therefore, the amount of credible excess inflation for period 2 is not limited above.

Third, we have shown that price stickiness eliminates price-level indeterminacy under optimal policy. Thus, the equilibrium choice, once the discount factor shock abated and the ZLB ceases binding, is not arbitrary but well defined. With a nominal anchor, optimal forward guidance policy aims to bring the price level back to the target price level $p^{\star}$ in period 3 . Therefore, in our model the new equilibrium choice is not arbitrary, as under inflation targeting (Cochrane, 2013), but optimal.

Finally, we extended the model to allow for fiscal policy as commitment device. With the ZLB being binding, the market real rate of interest is above the natural (shadow) rate in period 1. So it is optimal to shift the path of fiscal policy relative to the optimal first best path by raising government spending (lowering taxes) in the first relative to the second period. In contrast, procyclical austerity policy induces even higher welfare losses than discretionary policy.

\section{References}

BARRo, R., AND D. Gordon (1983): "Rules, discretion and reputation in a model of monetary policy," Journal of Monetary Economics, 12(1), 101-121.

Benigno, P. (2009): "New-Keynesian Economics: An AS-AD View," NBER Working Paper 14824.

CAlvo, G. (1983): "Staggered prices in a utility-maximizing framework," Journal of Monetary Economics, $12(3), 383-398$.

Campell, J., C. Evans, J. Fisher, A. Justiniano, C. Calomiris, and M. Woodford (2012): "Macroeconomic Effects of Federal Reserve Forward Guidance," Brookings Papers on Economic Activity, pp. 1-80.

Cochrane, J. (2013): "The New-Keynesian Liquidity Trap," Working Paper.

Eggertsson, G. (2006): "The Deflation Bias and Committing to Being Irresponsible," Journal of Money, Credit, and Banking, 38(2), 283-321.

(2011): "What Fiscal Policy is Effective at Zero Interest Rates," NBER Macroeconomics Annual 2010, 25(1), 59-112.

Eggertsson, G., And P. Krugman (2012): "Debt, Deleveraging, and the Liquidity Trap: A FisherMinsky-Koo Approach," The Quarterly Journal of Economics, 127(3), 1469-1513.

EgGertsson, G., And M. Woodford (2003): "Zero Bound on Interest Rates and Optimal Monetary Policy," Brookings Papers on Economic Activity, 1, 139-233.

Hatcher, M., And P. Minford (2014): "Stabilization policy, rational expectations and price-level versus inflation targeting: a survey," CEPR Discussion Paper No. 9820.

Krugman, P. (1998): "It's Baaack: Japan's Slump and the Return of the Liquidity Trap," Brookings Papers on Economic Activity, (2), 137-205.

Werning, I. (2012): "Managing a Liquidity Trap: Monetary and Fiscal Policy," Working Paper.

Woodford, M. (2003): "Inflation Targeting and Optimal Monetary Policy," in Annual Economic Policy Conference. Federal Reserve Bank of St. Louis.

Woodford, M. (2011): "Simple Analytics of the Government Expenditure Multiplier," American Economic Journal: Macroeconomics, (3), 1-35. 
Wu, J., AND F. XiA (2014): "Measuring the Macroeconomic Impact of Monetary Policy at the Zero Lower Bound," Working Paper.

\section{A Optimal Government Spending: FOCs}

Let $\mu$ and $\delta$ denote the Langrange parameters on constraint (5.3) and (5.4), respectively. Given that policy announcements of paths $\left\{p_{t}\right\}_{t=2}^{3}$ and $\left\{g_{t}\right\}_{t=2}^{3}$ are perfectly credible according to Assumption 1, we can drop expectation operators. The first order necessary conditions for the optimization problem described by Equations (5.2)-(5.4) are given by

$$
\begin{aligned}
& \left(p_{1}\right): \Lambda_{1}\left[p_{1}-p^{\star}\right]+\frac{\eta_{u}}{\kappa_{1}}\left(\frac{1}{\kappa_{1}}\left[p_{1}-p^{\star}\right]-g_{1}\right)-\mu=0 \\
& \left(p_{2}\right): \frac{1}{1+\rho_{1}}\left\{\Lambda_{2}\left[p_{2}-p^{\star}\right]+\frac{\eta_{u}}{\kappa_{2}}\left(\frac{1}{\kappa_{2}}\left[p_{2}-p^{\star}\right]-g_{2}\right)\right\}+\frac{\kappa_{1}\left(\kappa_{2}+\tilde{\sigma}\right)}{\kappa_{2}\left(\kappa_{1}+\tilde{\sigma}\right)} \mu-\delta=0 \\
& \left(p_{3}\right): \frac{1}{\left(1+\rho_{1}\right)(1+\bar{\rho})}\left\{\Lambda_{3}\left[p_{3}-p^{\star}\right]+\frac{\eta_{u}}{\kappa_{3}}\left(\frac{1}{\kappa_{3}}\left[p_{3}-p^{\star}\right]-g_{3}\right)\right\}+\frac{\kappa_{2}\left(\kappa_{3}+\tilde{\sigma}\right)}{\kappa_{3}\left(\kappa_{2}+\tilde{\sigma}\right)} \delta=0 \\
& \left(g_{1}\right): \eta_{g} g_{1}-\eta_{u}\left(\frac{1}{\kappa_{1}}\left[p_{1}-p^{\star}\right]-g_{1}\right)+\frac{\kappa_{1}}{\kappa_{1}+\tilde{\sigma}} \mu=0 \\
& \left(g_{2}\right): \frac{1}{1+\rho_{1}}\left\{\eta_{g} g_{2}-\eta_{u}\left(\frac{1}{\kappa_{2}}\left[p_{2}-p^{\star}\right]-g_{2}\right)\right\}-\frac{\kappa_{1}}{\kappa_{1}+\tilde{\sigma}} \mu+\frac{\kappa_{2}}{\kappa_{2}+\tilde{\sigma}} \delta=0 \\
& \left(g_{3}\right): \frac{1}{\left(1+\rho_{1}\right)(1+\bar{\rho})}\left\{\eta_{g} g_{3}-\eta_{u}\left(\frac{1}{\kappa_{3}}\left[p_{3}-p^{\star}\right]-g_{3}\right)\right\}-\frac{\kappa_{2}}{\kappa_{2}+\tilde{\sigma}}=0 \\
& (\mu): p_{1}-p^{\star}=\frac{\kappa_{1}\left(\kappa_{2}+\tilde{\sigma}\right)}{\kappa_{2}\left(\kappa_{1}+\tilde{\sigma}\right)}\left[p_{2}-p^{\star}\right]+\frac{\kappa_{1}}{\kappa_{1}+\tilde{\sigma}}\left(g_{1}-g_{2}\right)-\frac{i_{1}^{S}-\rho_{1}}{\kappa_{1}+\tilde{\sigma}} \\
& (\delta): p_{2}-p^{\star}=\frac{\kappa_{2}\left(\kappa_{3}+\tilde{\sigma}\right)}{\kappa_{3}\left(\kappa_{2}+\tilde{\sigma}\right)}\left[p_{3}-p^{\star}\right]+\frac{\kappa_{2}}{\kappa_{2}+\tilde{\sigma}}\left(g_{2}-g_{3}\right)-\frac{\kappa_{2} \tilde{\sigma}}{\kappa_{2}+\tilde{\sigma}}\left[i_{2}^{S}-\bar{\rho}\right]
\end{aligned}
$$

with with $\Lambda_{1} \equiv \frac{\varphi}{\kappa_{1}^{2}}+\theta \frac{\alpha_{1}+\alpha_{2}}{1-\alpha_{1}-\alpha_{2}}, \Lambda_{2} \equiv \frac{\varphi}{\kappa_{2}^{2}}+\theta \frac{\alpha_{1}}{1-\alpha_{1}}$ and $\Lambda_{3} \equiv \frac{\varphi}{\kappa_{3}^{2}}+\theta \frac{\alpha_{1} \lambda}{\alpha_{1} \lambda}$. We can use the fourth and sixth equation to solve for $g_{1}$ and $g_{3}$ directly:

$$
\begin{aligned}
g_{1} & =\frac{\eta_{u}\left(\kappa_{1}+\tilde{\sigma}\right)-\kappa_{1}^{2} \tilde{\Lambda}_{1}}{\kappa_{1}\left(\kappa_{1}+\tilde{\sigma}\right)\left(\eta_{g}+\eta_{u}\right)-\kappa_{1} \eta_{u}}\left[p_{1}-p^{\star}\right] \equiv \Sigma_{1}\left[p_{1}-p^{\star}\right] \\
g_{3} & =\frac{\kappa_{3} \tilde{\Lambda}_{3}-\eta_{u}\left(\kappa_{3}+\tilde{\sigma}\right)}{\eta_{u}-\left(\kappa_{3}+\tilde{\sigma}\right)\left(\eta_{g}+\eta_{u}\right)}\left[p_{3}-p^{\star}\right]
\end{aligned}
$$

For any parameter calibration it holds that $\Sigma_{1}<0$, i.e. independent of commitment and the ZLB, optimal fiscal policy always reacts countercyclical in period 1. Eliminating Lagrange- 
Parameters and summarizing further yields:

$$
\begin{aligned}
0= & \frac{\tilde{\Lambda}_{2}}{1+\rho_{1}}\left[p_{2}-p^{\star}\right]-\frac{\eta_{u}}{\kappa_{2}\left(1+\rho_{1}\right)} g_{2}+\frac{\kappa_{1}\left(\kappa_{2}+\tilde{\sigma}\right)}{\kappa_{2}\left(\kappa_{1}+\tilde{\sigma}\right)} \tilde{\Lambda}_{1}\left[p_{1}-p^{\star}\right]-\frac{\eta_{u}(\kappa 2+\tilde{\sigma})}{\kappa_{2}\left(\kappa_{1}+\tilde{\sigma}\right)} g_{1} \\
& +\frac{\eta_{u}\left(\kappa_{2}+\tilde{\sigma}\right)}{\kappa_{2}\left(1+\rho_{1}\right)(1+\bar{\rho})}\left[p_{3}-p^{\star}\right]-\frac{\left(\kappa_{2}+\tilde{\sigma}\right)\left(\eta_{g}+\eta_{u}\right)}{\kappa_{2}\left(1+\rho_{1}\right)(1+\bar{\rho})} g_{3}=0 \\
0= & \frac{\eta_{u}}{\kappa_{2}\left(1+\rho_{1}\right)}\left[p_{2}-p^{\star}\right]-\frac{\eta_{g}+\eta_{u}}{1+\rho_{1}} g_{2}+\frac{\kappa_{1} \tilde{\Lambda}_{1}}{\kappa_{1}+\tilde{\sigma}}\left[p_{1}-p^{\star}\right]-\frac{\eta_{u}}{\kappa_{1}+\tilde{\sigma}} g_{1}+\frac{\eta_{u}}{\left(1+\rho_{1}\right)(1 \bar{\rho})}\left[p_{3}-p^{\star}\right] \\
& -\frac{\eta_{g}+\eta_{u}}{\left(1+\rho_{1}\right)(1+\bar{\rho})} g_{3} \\
p_{1}-p^{\star}= & \frac{\kappa_{1}\left(\kappa_{2}+\tilde{\sigma}\right)}{\kappa_{2}\left(\kappa_{1}+\tilde{\sigma}\right)}\left[p_{2}-p^{\star}\right]+\frac{\kappa_{1}}{\kappa_{1}+\tilde{\sigma}}\left(g_{1}-g_{2}\right)-\frac{i_{1}^{S}-\rho_{1}}{\kappa_{1}+\tilde{\sigma}} \\
p_{2}-p^{\star}= & \frac{\kappa_{2}\left(\kappa_{3}+\tilde{\sigma}\right)}{\kappa_{3}\left(\kappa_{2}+\tilde{\sigma}\right)}\left[p_{3}-p^{\star}\right]+\frac{\kappa_{2}}{\kappa_{2}+\tilde{\sigma}}\left(g_{2}-g_{3}\right)-\frac{\kappa_{2} \tilde{\sigma}}{\kappa_{2}+\tilde{\sigma}}\left[i_{2}^{S}-\bar{\rho}\right]
\end{aligned}
$$

with $\tilde{\Lambda}_{t} \equiv \Lambda_{t}+\frac{\eta_{u}}{\kappa_{t}^{2}}, \forall t \in\{1,2,3\}$. Equations (A.1)-(A.6) is a system of 6 equations for 8 unknowns. Using, $i_{1}^{S}=0$ (ZLB in period 1) and $p_{3}=p^{\star}$ (ZLB not binding in $t=2$ ) or $i_{2}^{S}=0$ (ZLB binding in $t=2$ ), it can be solved for optimal policy. 